\title{
O PRÉ-VESTIBULAR SOCIAL TEOREMA COMO LÓCUS DE DEMOCRATIZAÇÃO DO ACESSO AO ENSINO SUPERIOR E DA INICIAÇÃO Â DOCÊNCIA NA UENF
}

\author{
THE THEOREM SOCIAL PRE-VESTIBULAR COURSE AS A \\ LOCUS OF DEMOCRATIZATION OF ACCESS TO HIGHER \\ EDUCATION AN INITIATION TO TEACHING AT UENF
}

\author{
Carolina França Pessanha* \\ ORCID: https://orcid.org/0000-0001-8350-149X \\ Danieli Alves Porto** \\ ORCID: https://orcid.org/0000-0001-5793-8364 \\ Renata Maldonado da Silva*** \\ ORCID: https://orcid.org/0000-0001-7901-623X
}

\section{RESUMO:}

Este artigo tem como objetivo analisar a experiência do Pré-Vestibular Social Teorema, um projeto de extensão que funciona na Universidade Estadual do Norte Fluminense Darcy Ribeiro (UENF). O Teorema foi criado em 2004 para auxiliar estudantes que desejassem frequentar um curso pré-vestibular, mas que não dispunham dos recursos financeiros necessários. A pesquisa utilizou a análise documental e entrevistas semiestruturadas realizadas com os coordenadores e professores do curso. As contribuições teóricas de Zago (2009), Nascimento (2009) e Manchur; Suriani e Cunha (2013) foram utilizadas para estabelecer o corpo analítico do estudo. Os resultados obtidos confirmam a importância do desenvol-vimento de práticas extensionistas em instituições de ensino superior públicas. Além disso, a partir das análises dos resultados foi verificado que o Pré-Vestibular Social Teorema tem contribuído para o aprimoramento de experiências docentes dos pós-graduandos envolvidos no programa, e ampliado o acesso à educação superior para os estudantes oriundos das classes subalternas.

Palavras-chave: Pré-vestibulares sociais; Experiência docente; Democratização do ensino.

\section{ABSTRACT:}

This article aims to analyze the experience of the Theorem Social Pre-Vestibular course, an extension project established at the North Fluminense Darcy Ribeiro State University (UENF). Theorem was created in 2004 to assist students who wanted to attend a pre-university course, but did not have the necessary financial resources. The sampling design used document analysis and semi-structured interviews conducted with the coordinators and teachers of the course. The theoretical contributions by Zago (2009), Nascimento (2009), and Manchur, Suriani and Cunha (2013) were used to create or analyze the analytical body of the study. The results obtained confirm the importance of developing extension practices in public higher education institutions. In addition, the analysis of results confirms that participation in Theorem has contributed to the improvement of the teaching skills of the graduate students involved in the program, and expanded access to higher education for students from lower classes.

Keywords: University preparatory programs; Teaching experience; Democratization of education.

\footnotetext{
* Mestrado. Universidade Estadual do Norte Fluminense Darcy Ribeiro (UENF), Campos dos Goytacazes - RJ, Brasil. E-mail: carolfrancapessanha@gmail.com

** Licenciatura em Pedagogia. Universidade Estadual do Norte Fluminense Darcy Ribeiro (UENF), Campos dos Goytacazes - RJ, Brasil. E-mail: alves.danielly@ hotmail.com

*** Professora da Universidade Estadual do Norte Fluminense Darcy Ribeiro (UENF), Campos dos Goytacazes · RJ, Brasil. E-mail: r.maldonado@globo.com
} 


\section{Introdução}

O objetivo deste artigo é discutir o papel do Pré-Vestibular Social Teorema como um estratégico projeto extensionista desenvolvido pela Universidade Estadual do Norte Fluminense Darcy Ribeiro - UENF, que vem contribuindo para o processo de democratização do ensino superior e possibilitando o aprimoramento da prática docente pelos pós-graduandos da instituição, na região Norte Fluminense. O presente estudo foi desenvolvido por meio de pesquisa bibliográfica e análise documental relacionadas ao Pré-Vestibular Social Teorema, além da realização de entrevistas semiestruturadas com os coordenadores e professores do curso.

Os pré-vestibulares sociais fazem parte de um conjunto de iniciativas voltadas para o combate à desigualdade de acesso à educação superior, que tiveram início a partir da década de 1990, após o processo de redemocratização do Brasil. Isto ocorreu por meio da forte atuação dos movimentos sociais no período, que questionaram as desigualdades de acesso no âmbito do ensino superior pelas classes subalternas, que, historicamente, estiveram excluídas desta modalidade de ensino.

Nesse contexto, o Pré-Vestibular Social Teorema foi pensado pelos pósgraduandos da UENF para auxiliar os técnicos da universidade e seus familiares a aprimorarem seus conhecimentos apreendidos no decorrer do ensino médio, para que pudessem concorrer aos exames de acesso ao ensino superior, principalmente o Exame Nacional do Ensino Médio - ENEM. Posteriormente, o Teorema ampliou o seu caráter social, estendendo para todos os indivíduos que desejassem reforçar seus conhecimentos escolares e não dispusessem dos recursos financeiros necessários.

No entanto, além de auxiliar os alunos na consolidação dos conhecimentos necessários para a realização do ENEM, o Pré-Vestibular Social Teorema vem atuando como um espaço que tem oportunizado a iniciação à docência para os pós-graduandos da UENF, permitindo que estes atuem como professores no curso. Portanto, o Teorema tem cumprido dois principais objetivos na instituição: primeiramente, o de possibilitar que os alunos das classes subalternas ${ }^{1}$ ampliem seus conhecimentos para concorrer, em melhores condições de igualdade, aos exames de acesso ao ensino superior e, secundariamente, como lócus de experiência didática e pedagógica de pós-graduandos em seus processos de formação.

Em função disso, o artigo será dividido em quatro partes. Na primeira seção, será discutido o pioneirismo dos pré-vestibulares sociais como agentes que auxiliam os indivíduos das classes historicamente excluídas do ensino superior a realizarem seus exames de acesso, assim como suas principais características e as primeiras iniciativas no Brasil neste formato. Na segunda seção, será abordado o histórico da UENF e sua estratégica importância para a região Norte Fluminense, além do pioneirismo do Pré-Vestibular Social Teorema como prática extensionista da instituição. Na terceira, será discutido o Teorema como um lócus institucional que possibilita a iniciação à docência pelos alunos das pós-graduações da 
universidade, além de reforçar a função social do curso. Na última seção, pretende-se sinalizar a importância do projeto Teorema como um ator estratégico na contribuição de ampliar o acesso ao ensino superior das classes subalternas na região Norte Fluminense.

\section{Um breve histórico dos cursos pré-vestibulares sociais no Brasil}

Os cursos pré-vestibulares sociais, também denominados populares, alternativos ou comunitários, são frutos das demandas dos movimentos sociais, sobretudo dos que se articularam com os projetos de educação popular, no contexto do período de redemocratização da sociedade brasileira, após o encerramento dos 21 anos de governos ditatoriais militares ${ }^{2}$. De acordo com Zago (2009), estes fazem parte das:

\footnotetext{
Iniciativas coletivas pela democratização do país. Seu surgimento e ampliação, no Brasil, estão diretamente relacionados à problemática das desigualdades de acesso ao ensino superior - especialmente da rede pública - que ganharam maior visibilidade com a quase universalização do ensino fundamental e a ampliação do ensino médio (ZAGO, 2009, p. 254).
}

Segundo a mesma autora acima citada, a expansão do ensino básico também provocou o aumento pela demanda no ensino superior, ampliando, consideravelmente, a relação candidato-vaga, principalmente nas instituições públicas (ZAGO, 2009). Esse quadro aumentou a demanda pelos estudantes que não conseguiam se inserir nas instituições de ensino superior e fortaleceu os movimentos sociais que defendiam o modelo público de ensino e almejavam maior inclusão de determinados segmentos sociais nas universidades. Portanto, "dentre as propostas mais relevantes criadas no período pós-ditatorial, destacam-se o Movimento dos Sem Universidade, as alterações nas formas de ingresso e, sobretudo, os cursinhos pré-vestibulares comunitários" (MOEHLECKE; CATANI, 2006, p. 50).

Dentre os mais importantes protagonistas em busca da democratização do acesso ao ensino superior para as minorias, destaca-se o Pré-Vestibular para Negros e Carentes - PVNC, criado em 1993 por setores articulados à Pastoral do Negro de São Paulo. O PVNC surgiu na Baixada Fluminense, a partir da constatação das dificuldades de acesso dos estudantes das classes populares às universidades. Além disso, o curso buscou desenvolver estratégias que combatessem as discriminações raciais a que, historicamente, a população negra vem sendo submetida, sobretudo no campo educacional.

De acordo com Justino (2002), essa proposta se baseava em duas afirmativas: primeiramente, em função da péssima qualidade do ensino médio da região da Baixada Fluminense, que dificultava que os estudantes - em sua maioria pobres e negros, chegassem às universidades. Em segundo lugar, pela constatação de que menos de 5\% dos estudantes universitários no período eram negros. Portanto, ao final do ano de 1992, na Igreja de São João de Meriti, iniciaram-se as discussões para a organização de um pré-vestibular que 
capacitasse os estudantes da região a concorrerem ao exame pré-vestibular da PUC-SP e das universidades públicas do estado do Rio de Janeiro. De acordo com Justino:

\begin{abstract}
O grupo que iniciou a articulação para a formação do curso era composto por professores de ensino médio e militantes dos grupos católicos de Agentes de Pastoral Negros (APN) e do Grupo de Reflexão sobre Negros e Indígenas (GRENI). Esse grupo iniciou os contatos com outros professores, buscou escolas que pudessem ceder uma sala para a realização das aulas, bem como realizaram o trabalho de divulgação e reuniões com os primeiros alunos interessados. A partir desses contatos o grupo foi se ampliando, a ideia começou a se materializar e, em junho de 1993, iniciaram-se as aulas do curso. A esse curso foi dado o nome de Curso Pré-Vestibular para Negros e Carentes (JUSTINO, 2002, p.14)
\end{abstract}

É importante ressaltar que o surgimento dos pré-vestibulares sociais, de acordo com Nascimento (2012), constituiu a base social dos movimentos reivindicadores por políticas de cotas e, mediante acordos com as instituições privadas de ensino, deu origem ao Programa Universidade para Todos - ProUni, criado pelo Governo Federal, posteriormente, em 2005. De acordo com o mesmo autor, "ainda em 1993, os coordenadores do PVNC iniciaram um acordo com a PUC-Rio, que depois se desdobraram para outras instituições privadas de ensino, concedendo bolsas integrais aos egressos dos pré-vestibulares populares" (NASCIMENTO, 2012, p. 5). Segundo Justino (2002), já no primeiro ano de trabalho, o PVNC obteve a taxa de aprovação de $34 \%$ nas principais instituições de ensino superior do Rio de Janeiro - UERJ, UFRJ, UFF e PUC-Rio, comprovando o caráter inclusivo do curso no que se refere à democratização do acesso ao ensino superior para as comunidades pobres. Isso, ainda, possibilitou que novos núcleos fossem organizados e, atualmente, mais de 150 cursos existentes no estado do RJ foram criados a partir do PVNC.

Entretanto, de acordo com Nascimento (2002), os objetivos dos prévestibulares populares ultrapassam o projeto de preparação para o exame pré-vestibular, que, atualmente, foi substituído pelo Exame Nacional do Ensino Médio, criado em 1998 e, a partir de 2009, vem sendo utilizado como principal mecanismo de seleção para o ingresso no ensino superior. Segundo o mesmo autor, existem preocupações políticas, que estão presentes nos discursos, nas propostas e nas suas práticas, que visam, em última instância, construir uma nova consciência em seus educandos, problematizando as lógicas de exclusão presentes na sociedade brasileira. Portanto, os cursos atuam como um espaço no qual os setores marginalizados buscam reafirmar sua cidadania e pleiteiam sua existência como sujeitos políticos, nos quais seus direitos estejam assegurados (NASCIMENTO, 2002).

No decorrer desse mesmo processo de implementação do PVNC, surgiram outras duas importantes experiências populares de ensino pré-vestibular: o curso criado pela Associação dos Trabalhadores em Educação da Universidade Federal do Rio de Janeiro - UFRJ, no ano de 1986, através do projeto Universidade para Trabalhadores, que era extensivo também aos moradores das comunidades pobres, e o curso Mangueira Vestibulares, em 1992, com o objetivo de atender aos estudantes da comunidade do morro da mangueira, no município do Rio de Janeiro. 
Os pré-vestibulares sociais foram organizados de forma não convencional, buscando preparar os alunos oriundos das classes subalternas para o exame de seleção ao ensino superior. De acordo com a produção acadêmica sobre esse assunto, os pré-vestibulares sociais são iniciativas sem fins lucrativos, no qual participam também instituições religiosas, associações comunitárias, universidades, estudantes e professores. No entanto, de acordo com Zago (2009), um traço comum desses cursos é o de buscar "democratizar e possibilitar o acesso a uma população que, historicamente, vem sendo excluída do ensino superior, tais como negros, famílias de baixa renda, estudantes das escolas públicas e moradores dos bairros populares" (ZAGO, 2009, p. 255). De acordo com a mesma autora, as principais características deste modelo de ensino seriam:

\begin{abstract}
[...] atendimento aos setores, grupos ou frações de excluídos socialmente do acesso ao ensino superior e egressos de escolas públicas; são cursos gratuitos na sua maioria ou que cobram uma taxa que varia entre $5 \%$ a $10 \%$ do salário mínimo para despesas básicas relacionadas a manutenção das suas estruturas, transporte para professores e outros colaboradores; [...] na maioria dos pré-vestibulares populares há um eixo curricular denominado "cultura e cidadania", nominação da disciplina obrigatória que privilegia um trabalho educativo voltado para o exercício da cidadania e este compreende a formação de uma consciência crítica frente aos problemas políticos, sociais e de discriminação racial no país; seu corpo docente e administrativo está apoiado em um trabalho voluntario; poucos são os cursos que possuem sede própria, eles funcionam em locais bastante diversificados como: escolas, universidades, instituições religiosas, associações comunitárias, entre outros (ZAGO, 2008, p. 152).
\end{abstract}

Em geral, os cursos pré-vestibulares sociais são iniciativas desenvolvidas com base no trabalho voluntário. Dessa forma, em sua grande maioria, a equipe de professores e de coordenadores presentes nesses cursos é formada por estudantes de graduação, pós-graduação e profissionais da educação, que oferecem seu trabalho de forma voluntária (ZAGO, 2008). Assim sendo, notou-se que, além de buscar promover na sociedade brasileira a igualdade de oportunidades no âmbito educacional, por meio do acesso das classes subalternas às universidades e às instituições de ensino superior, os prévestibulares sociais possibilitam também que estudantes de graduação e pós-graduação complementem sua formação acadêmica por meio da experiência docente junto aos setores historicamente marginalizados socialmente.

De acordo com Nascimento (2009), "os pré-vestibulares mostraram-se como uma necessidade, pois tem demonstrado ser a única porta de acesso de jovens pobres e negros na universidade pública" (NASCIMENTO, 2009, p. 38). Portanto, nota-se que o pré-vestibular vem exercendo o papel de agente de democratização e universalização, isto é, tem buscado promover na sociedade brasileira a igualdade de oportunidades no âmbito educacional, por meio do acesso das camadas populares às universidades e às instituições de ensino superior. Assim, observou-se que, independentemente do movimento que os origina, os cursos pré-vestibulares sociais "são baseados no coletivismo, na solidariedade e na crença de que o acesso à educação é um meio potencializador das transformações sociais. [...] e tem como elemento norteador o princípio da igualdade social e educacional" (SILVA, 2006, p. 33). 


\section{A criação da UENF e o Pré-Vestibular Social Teorema}

No contexto da redemocratização brasileira, na região Norte Fluminense (aproximadamente $250 \mathrm{~km}$ do município do Rio de Janeiro), foi implementada a segunda universidade estadual no Rio de Janeiro: a Universidade Estadual do Norte Fluminense Darcy Ribeiro - UENF, no ano de 1993. Sua criação foi proposta pela iniciativa dos movimentos sindicais, das lideranças políticas regionais, da imprensa local e, sobretudo, da população campista, que realizou um abaixo-assinado que reuniu quase 8 mil assinaturas ao longo do ano de 1989.

A partir disso, a UENF se tornou a primeira universidade pública a ser instalada na região Norte Fluminense. Foi idealizada pelo antropólogo Darcy Ribeiro, designado pelo governador do Estado no Rio de Janeiro, na época, Leonel Brizola. O professor Darcy Ribeiro pretendeu instaurar um modelo inovador com uma estrutura apoiada em laboratórios de pesquisa e não em departamentos, como as instituições federais de ensino, de modo que os alunos de graduação estivessem articulados aos projetos dos professores já nos semestres iniciais de sua formação. Além disso, desde o início de seu funcionamento, a UENF dispõe de um corpo docente integralmente composto por doutores, atuando em regime de dedicação exclusiva, no qual foi pioneira. Além disso, Darcy Ribeiro apontou a importância da UENF para o desenvolvimento local e para a formação de recursos humanos especializados na região Norte Fluminense e entorno.

A UENF, atualmente, dispõe de 19 cursos de graduação, 16 programas de pósgraduação stricto sensu e 1 lato sensu, totalizando em torno de 3.500 alunos e 330 professores. Desde 2003, a UENF, juntamente com a Universidade Estadual do Rio de Janeiro - UERJ, foi pioneira na implantação das ações afirmativas por meio da Lei Estadual $n^{\circ}$. 4.151, que instituiu reserva de vagas para o ingresso de alunos pretos, pardos e indígenas nas universidades estaduais do Estado do Rio de Janeiro. A partir de 2015, as políticas de ações afirmativas, na modalidade de cotas, também foram estendidas para a pós-graduação.

Diante disso, com o objetivo de ampliar a entrada da comunidade da região e, principalmente, dos funcionários da UENF nas instituições superiores de ensino, é que foi pensado o Pré-Vestibular Social Teorema. Este é um projeto de extensão da UENF que foi idealizado nos anos de 2002 e 2003 por pós-graduandos da universidade, em parceria com a Pró-Reitoria de Extensão e Assuntos Comunitários e a Pró-Reitoria de PósGraduação da UENF. Suas atividades foram iniciadas em julho de 2004 e, atualmente, a coordenação e o corpo docente do curso são compostos por doutorandos e mestrandos de distintos centros da universidade.

Inicialmente, o projeto buscava atender estritamente os trabalhadores da UENF. No entanto, gradativamente, o Teorema incorporou o atendimento à comunidade de Campos dos Goytacazes e de áreas limítrofes. Destaca-se a importância deste projeto para o município, pois este é: 
[...] o maior do interior fluminense, é um polo universitário, com dezenas de universidades privadas e públicas, entre elas a Universidade Estadual do Norte Fluminense Darcy Ribeiro (UENF), o campus da Universidade Federal Fluminense (UFF), a Universidade Federal Rural do Rio de Janeiro (UFFRJ), o Instituto Federal Fluminense (IFF). Todas juntas oferecem expressiva oferta de vagas em graduações de áreas distintas, que vão de licenciaturas a cursos superiores de tecnologia e engenharias (BARRETO et al., 2015, p. 1663).

O Pré-Vestibular Social Teorema, hoje amparado institucionalmente pelo Colegiado Acadêmico da Universidade, é acompanhado pela Pró-Reitoria de Extensão e Assuntos Comunitários, e recebe apoio da Diretoria do Centro de Ciências e Tecnologias Agropecuárias (CCTA/UENF). Financeiramente, o curso é subsidiado com o dinheiro das suas inscrições, único valor cobrado aos estudantes, e recebe ajuda financeira da PróReitoria de Extensão no que tange ao fornecimento de materiais de consumo. Nos últimos anos, também tem recebido verbas por meio da submissão de trabalhos relacionados ao projeto, na Fundação de Amparo à Pesquisa do Estado do Rio de Janeiro - FAPERJ.

O Teorema é dirigido "a todos os interessados que já concluíram ou que estão frequentando o último ano do Ensino Médio ou equivalente e que desejam realizar as provas de acesso às universidades, mas que não têm condições de arcar com os custos dos cursos preparatórios particulares" (FARIAS, 2015, p. 9).

Atualmente, são disponibilizadas 210 vagas por ano, divididas em três turmas de 70 alunos cada. Esses alunos são atendidos por uma equipe composta por 3 coordenadores e 15 professores. No total, são ministradas 15 disciplinas: Português / Gramática, Literatura / Redação, Matemática I e II, Física I e II, Biologia I e II, Química orgânica, Química inorgânica, História geral, História do Brasil, Geografia, Botânica e Inglês, no período de segunda a sexta-feira, das 18 às 22 horas, e aos sábados, das 8 às 13 horas.

Contudo, apesar da iniciativa do pré-vestibular social em contribuir para que os alunos consigam ultrapassar as barreiras sociais que dificultam seu acesso ao ensino superior, em muitos casos, os discentes não dispõem de condições de frequentar diariamente as aulas ministradas. Portanto:

\footnotetext{
Como meio de combater essa adversidade e contribuir para a democratização do ensino, surgiu o Pré-vestibular Social Teorema na modalidade a distância, iniciado em 2013, com o objetivo de preparar os alunos - que precisam trabalhar no horário do ensino preparatório ou que não tem acesso ao local do curso, por ser distante de sua residência, entre outros motivos - para o Exame Nacional do Ensino Médio (ENEM) e outros vestibulares. Seu público alvo inicialmente foram os alunos atendidos no curso presencial, por ser ainda uma experiência piloto. No entanto a partir de 2015 ampliou-se o acesso ao curso para o público externo ao Teorema presencial (JASMIN et al., 2018, p. 2).
}

Inicialmente, de acordo com os autores acima citados, o curso estava disponível no Ambiente Virtual de Aprendizagem - AVA Moodle, no qual havia administradores responsáveis pela inserção dos discentes, além dos tutores, que retiravam os conteúdos elaboradoras na modalidade presencial e encaminhavam para a plataforma. 
Contudo, os autores afirmaram que essa estratégia não foi suficiente para garantir a permanência dos alunos, pois, dos 118 alunos inscritos nessa modalidade, 26,27\% acessaram assiduamente a plataforma, 37,29\% frequentaram algumas vezes (ao menos uma disciplina) e $36,44 \%$ nunca frequentaram as aulas.

Em função disso, em 2016, o curso foi restruturado, ampliando o leque de opções da utilização da plataforma Moodle (JASMIN et al., 2018). Portanto, ainda há desafios a serem enfrentados pelo curso Teorema, com o objetivo de assegurar maior permanência dos discentes que optam pela utilização do pré-vestibular social na modalidade a distância. Entretanto, diferentemente do que ocorre na EAD, na modalidade presencial, $80 \%$ dos estudantes chegam ao final do curso, segundo informações concedidas pela coordenação.

\section{Pré-Vestibular Social Teorema e a iniciação à docência}

Como já mencionado, o Pré-Vestibular Social Teorema funciona como um espaço de iniciação à docência para os pós-graduandos da UENF. Nesse sentido, Manchur, Suriani e Cunha (2013) chamam a atenção sobre a importância de projetos extensionistas desenvolvidos pelas instituições universitárias, possibilitando que os alunos das licenciaturas produzam metodologias de ensino que complementem sua formação acadêmica. Além disso, os autores destacam que, através dos projetos de extensão que envolvam a prática docente, os alunos podem articular o saber apreendido na universidade com a "aplicabilidade da sua profissão na sociedade” (MANCHUR; SURIANI; CUNHA, 2013, p. 339).

De acordo com Fernandes et al:

Parte-se do princípio de que a formação do acadêmico é tomada como fundamento do processo educativo implementado na universidade, uma vez que contribuirá para sua compreensão como ser socialmente responsável livre, capaz de refletir sobre o vivido e o aprendido em sala de aula e outros espaços, como na comunidade, que vão construindo cotidianamente sua identidade pessoal e profissional alicerçadas na busca do saber ser, saber fazer e saber aprender, ou seja, na formação de suas competências (FERNANDES et al., 2012, p.3).

Portanto, trata-se de um espaço de reconhecimento pelos estudantes em promover a mediação entre a construção do conhecimento em sala de aula, de modo conjunto com os estudantes das classes subalternas que frequentam o curso. Ressalta-se, ainda, a possibilidade de ter uma formação mais ampla na pós-graduação e de "aliar a experiência do magistério e as exigências acadêmicas de estágio como uma atividade social" (ZAGO, 2009, p. 260).

No caso especificamente do Pré-Vestibular Social Teorema, de acordo com um dos coordenadores do curso, há um percentual significativo de pós-graduandos que 
durante todo o seu tempo de permanência na universidade auxiliam no curso. Esses pósgraduandos passam a integrar o corpo docente do pré-vestibular por meio de aprovação em processo seletivo, que é aberto de acordo com a necessidade de preenchimento de vagas. Assim sendo, os mestrandos e doutorandos da UENF, interessados em atuar no Pré-Vestibular Social Teorema, devem concorrer a um processo seletivo, composto de análise de currículo e prova aula.

Importante registrar que diferentemente da seleção dos candidatos a professores do curso presencial, o processo seletivo para os tutores da modalidade EAD do curso é composto apenas por "análise de currículo com cursos ou experiência voltada a EAD” (FARIAS, 2015, p. 16).

Aos pós-graduandos aprovados no processo e convocados para integrar o corpo docente é oferecida uma bolsa no valor de $420^{3}$ reais, para o cumprimento de uma carga horária de 6 horas semanais. No caso dos tutores da modalidade EAD, estes "possuem uma carga horária de vinte horas semanais, sendo dez horas presenciais e dez horas à distância, atentos à plataforma para orientação dos alunos" (FARIAS, 2015, p. 16).

Cabe destacar que, segundo os coordenadores do curso, a bolsa ofertada contribui para diminuir a rotatividade dos professores que atuam no pré-vestibular. Além disso, a bolsa ajuda a complementar a renda do pós-graduando, que está se dedicando exclusivamente às atividades acadêmicas naquele momento.

Além da preparação e execução das aulas, os pós-graduandos também são responsáveis pela confecção do material. Desse modo, nota-se que o curso contribui com a formação acadêmica e profissional desses pós-graduandos ao possibilitar que eles desenvolvam atividades pedagógicas junto aos alunos que, historicamente, vêm sendo marginalizados socialmente, possibilitando, assim, que estes ganhem ou aprimorem sua experiência como docentes.

Zago (2009), em estudo sobre a trajetória docente em pré-vestibulares sociais, destaca que muitos professores decidem atuar nesse tipo de instituição, apesar da baixa remuneração, pela proposta de promover a democratização do acesso ao ensino superior, contribuindo para a diminuição das desigualdades sociais. De acordo com a autora, a "opção" pelo trabalho docente nesse tipo de instituição se relacionaria:

[...] de uma motivação inicial geralmente associada uma identificação entre sua própria trajetória social e escolar e aquela dos alunos (baixo capital econômico e cultural familiar, egressos de escola pública, escolaridade associada ao trabalho, conforme características já destacadas) e uma mobilização, imbuída de uma espécie de missão - voltada para a redução das desigualdades sociais da qual a maior parte sofreu os efeitos (ZAGO, 2009, p. 259).

Portanto, de acordo com as ideias da autora, a adesão ao trabalho docente nos pré-vestibulares sociais é construída a partir de inúmeras mediações, tais como "a origem social, o passado escolar, as experiências de várias ordens (de formação, de opções políticas, 
religiosas, familiares, profissionais etc.)" (ZAGO, 2009, p. 265). A escolha pela atuação como docente em pré-vestibular social promove a criação do chamado "habitus professoral", no qual a identidade profissional se insere (ZAGO, 2009). Nesse sentido, o processo de desenvolvimento profissional é construído ao longo da carreira docente, sendo influenciado por uma pluralidade de elementos, das quais se destacam a origem social, o capital cultural existente no meio familiar e a cultura política no qual os indivíduos estão inseridos.

De acordo com alguns professores do Pré-vestibular Social Teorema, apesar da complementação de 420 reais na bolsa, essa não foi a principal motivação que os levou a atuar no curso. Segundo esses professores, a busca por experiência profissional, vinculada à vontade de contribuir com uma questão social, foi a principal motivação para participarem do processo seletivo do Pré-Vestibular Social Teorema para atuarem como professores.

Portanto, constata-se que há um consenso da equipe pedagógica do curso no que tange ao reconhecimento do Pré-Vestibular Social Teorema como um potencial espaço de redução das desigualdades sociais e que possibilita o acesso à educação às classes economicamente desfavorecidas, além de funcionar como um lócus de iniciação à docência.

\section{Pré-Vestibular Social Teorema enquanto agente democratizador do acesso ao ensino superior na região Norte Fluminense}

Como já abordado, o Pré-Vestibular Social Teorema foi desenvolvido com o objetivo primeiro de auxiliar na atenuação da desigualdade do acesso ao ensino superior, por meio da oferta de preparo para os exames vestibulares. Notou-se que, a princípio, o Teorema era voltado para os funcionários da UENF que desejassem ingressar no ensino superior. Entretanto, posteriormente, o curso passou a atender aos estudantes da Cidade de Campos dos Goytacazes e regiões vizinhas, sobretudo, por meio do curso em formato EAD.

O Pré-Vestibular Social Teorema é direcionado aos estudantes oriundos da rede pública de ensino. No entanto, o fato de o processo seletivo dos alunos ser baseado apenas em realização de inscrição, de acordo com a ordem de chegada, torna a participação no curso possível para estudantes tanto da rede pública quanto da privada de ensino. Desse modo, constata-se que o Pré-Vestibular Social Teorema não realiza processo seletivo baseado em prova e/ou análise socioeconômica, métodos utilizados por alguns pré-vestibulares, como no caso de um segundo pré-vestibular social em funcionamento também na UENF. Todavia, segundo a coordenação do curso, mais de $80 \%$ dos alunos que procuram o curso são oriundos das escolas públicas.

É importante salientar que o curso tem um número de vagas limitado, um total de 210, de forma que assim que se chega a esse limite, é criada uma lista de espera que vai sendo contemplada durante o ano, em caso de evasão dos participantes. As 
inscrições para o curso iniciam em outubro e se encerram em janeiro. A divulgação do processo seletivo para o pré-vestibular é feita por meio das redes sociais, canais de televisão e professores que se direcionam às escolas públicas da região, a fim de levar informações a respeito da abertura de edital do curso.

O Pré-Vestibular Social Teorema é um curso gratuito e dirigido àqueles que não possuem condições de arcar com os custos de um curso preparatório privado. Dessa forma, o único valor cobrado aos estudantes é uma taxa de 50 reais, referente a 30 reais da matrícula e 20 reais da inscrição, não sendo cobrado mais nenhum valor aos estudantes durante todo o curso. Importante ressaltar que o valor angariado por meio da matrícula e da inscrição é revertido na confecção de material didático para as aulas.

Com relação à modalidade EAD do pré-vestibular, só tem seu edital aberto após o fechamento do edital presencial. Os estudantes dessa modalidade recebem o material didático em casa e assistem a aulas disponibilizadas semanalmente na plataforma do curso, enquanto "as dúvidas dos alunos são respondidas online pela tutoria por meio de Blog, e-mail, fórum e chat" (FARIAS, 2015, p. 9).

Segundo a coordenação do curso, a adesão a esse modelo de educação expandiu o número de alunos do projeto, pois muitos discentes, em função das dificuldades de transporte público existentes na região, não conseguiam frequentar diariamente as aulas no pré-vestibular. Além disso, a modalidade EAD possibilitou que estudantes de regiões vizinhas da Cidade de Campos tivessem acesso ao curso.

Desde o início de suas atividades, o Pré-Vestibular Social Teorema vem obtendo ótimos índices de aprovações de seus alunos em universidades públicas e privadas, de acordo com diagnósticos realizados pela coordenação do curso. Conforme registrado da página online do curso, no ano de 2019, 21 estudantes que cursaram o Teorema alcançaram acesso no ensino superior em instituições públicas e privadas. Segundo um dos seus coordenadores:

\begin{abstract}
“A inserção dos discentes do Teorema nas instituições de ensino superior da região reafirma a importância de iniciativas como as do Pré-Vestibular Social Teorema, em que, apesar da infraestrutura oferecida pela universidade não ser considerada ideal, o projeto contribuiu para a inserção de alunos que não poderiam custear um curso preparatório privado e, em função disso, teriam o seu acesso ao ensino superior comprometido" (Coordenador do Pré-Vestibular Social Teorema).
\end{abstract}

Como pode ser analisado a partir da fala do coordenador, o Pré-Vestibular Social Teorema, assim como muitos outros cursos dessa espécie espalhados pelo país, funciona em espaços cedidos pela universidade, o que influencia na oferta de uma infraestrutura adequada para o recebimento dos alunos. Desse modo, percebe-se que o fato de o curso obter apenas 3 salas de aula, que comportam o total de 70 alunos em cada, pode influenciar, negativamente, a atuação do professor, assim como o aprendizado dos alunos. 
Do ponto de vista pedagógico, quanto maior o número de alunos em uma sala de aula, maiores são as dificuldades apresentadas ao professor, no que diz respeito a perceber as dificuldades enfrentadas pelos alunos, assim como atender a todas possíveis dúvidas que possam aparecer em uma mesma aula.

Entretanto, apesar das dificuldades encontradas, o Pré-Vestibular Social Teorema tem buscado realizar seu trabalho voltado para a igualdade educacional de modo satisfatório. Assim sendo, nota-se que o curso vem buscando cumprir o objetivo pelo qual foi implementado, ao funcionar como espaço de promoção de auxílio no preparo para as provas vestibulares, oferecido de forma gratuita de forma presencial e na modalidade EAD. Portanto, salienta-se que o compromisso social do Pré-Vestibular Teorema com a promoção da democratização do ensino superior tem sido perseguido durante seus 16 anos de existência.

\section{Considerações finais}

O presente trabalho buscou discutir a importância que as iniciativas dos prévestibulares sociais possuem no auxílio à democratização do ensino superior brasileiro. Com destaque para o Pré-Vestibular Social Teorema, percebe-se que esses cursos vêm exercendo um duplo papel na sociedade: por um lado, possibilitam que se viabilize a democratização do acesso das camadas sociais historicamente excluídas ao ensino superior. Por outro lado, contribuem para a construção das práticas docentes, uma vez que exercem a função de funcionar como um espaço de estágio docente.

Como foi apontado ao longo do artigo, o município de Campos de Goytacazes e seu entorno é um importante polo universitário no Norte Fluminense, com uma quantidade expressiva de instituições superiores de ensino. Portanto, o Teorema vem auxiliando para que os estudantes das classes subalternas da região complementem seus conhecimentos apreendidos no ensino médio, contribuindo, portanto, para reduzir as barreiras socioeducacionais que os impedem de ter acesso ao ensino superior. A partir disso, o pré-vestibular social pode ser considerado um estratégico agente na região Norte Fluminense na formação de recursos humanos e de promoção para o desenvolvimento regional.

A iniciação à docência pelos estudantes de pós-graduação da UENF no PréVestibular Social Teorema é outro importante ponto a ser ressaltado. Além da possibilidade de criação de novas metodologias e práticas pedagógicas voltadas para este público-alvo, destaca-se a importância em ressaltar o viés social desta iniciativa, que tem o objetivo de também problematizar as desigualdades sociais presentes no sistema educacional brasileiro e o caráter excludente do direito à educação no país. 
Defende-se, a partir do estudo realizado, a criação de projetos que articulem as diversas instâncias da universidade (ensino-pesquisa-extensão) e a necessidade de promoção de projetos extensionistas nas universidades públicas. Estes, além de promoverem o enriquecimento das formações acadêmicas e profissionais dos estudantes da instituição, contribuem para o desenvolvimento social da região e da formação de recursos humanos, buscando atenuar situações de desigualdades socioeducacionais, como o exemplo dos cursos pré-vestibulares sociais.

\section{Referências}

BARRETO, S.R.; FARIAS, C.L.; BARROS, T.V.; SANTOS, P.C.; JASMIN, J.M.; CARVALHO, A.J.C. Os Desafios Do XXXX Para A Democratização Do Acesso Ao Ensino Superior: Resultados e Ações no Ano de 2015. Revista Philologus, Rio de Janeiro: CiFEFiL, ano 21, n. 63, Supl.: Anais da X CNLF, p. 1662-1671, set./dez., 2015. Disponível em: http://www.filologia.org.br/rph/ANO21/63supl/0119.pdf. Acesso em 24 jun. 2020.

DREIFUSS, R. A. 1964: a conquista do Estado. Ação política, poder e golpe de classes. Rio de Janeiro: Vozes, 1987.

FARIAS, C. L. Limites e dificuldades enfrentadas na utilização dos recursos tecnológicos do mooodle de um curso pré-vestibular social. 2015. 26 f. Trabalho de Conclusão de Curso (Especialização Lato Sensu em Planejamento, Implementação e Gestão da EAD) Universidade Federal Fluminense, São Francisco do Itabapoana, 2015.

FERNANDES, M. C. et al. Universidade e a extensão universitária: a visão dos moradores das comunidades circunvizinhas. Educação em Revista, Belo Horizonte, v. 28, n 4., p. 169-193, jun 2012. Disponível em: http://www.scielo.br/scielo.php?script=sci_arttext\&pid=S0102$46982012000400007 \&$ lang=pt. Acesso em 28/01/2015.

JASMIM, J. M. et al. O Pré-Vestibular Social Teorema na modalidade a distância. In: CONGRESSO INTERNACIONAL DE EDUCAÇÃO E TECNOLOGIAS, CIET: EnPED, 4., 2018, São Carlos. [Anais...]. São Carlos: UFSCar, 2018. Disponível em: https://cietenped.ufscar.br/submissao/index.php/2018/article/view/819. Acesso em: 26 jun. 2020.

JUSTINO, D.; DAVID, M. Desigualdades raciais e ensino superior no Brasil: O movimento negro e a luta pela democratização das universidades. Programa Regional de Becas CLACSO, 2002. Disponível em: http://bibliotecavirtual.clacso.org.ar/ar/libros/becas/2002/edu/diogo.pdf. Acesso em: 26 jun. 2020. 
MANCHUR, J.; SURIANI; A. L. A.; CUNHA, M. C. da. A contribuição de projetos de extensão na formação profissional de graduandos das licenciaturas. Ponta Grossa, Paraná: Revista Conexão, v. 9, n. 2, p.334-341, jul./dez. 2013.

MOEHLECKE, S.; CATANI, A. M. Reforma e expansão do acesso ao Ensino Superior: balanço e proposições. Brasília: Instituto Nacional de Estudos e Pesquisas Educacionais (Série Documental. Textos para discussão n. 23), p.49-71, 2006.

NASCIMENTO, E. P. Jovens e educação superior: as aspirações de estudantes de cursos pré-vestibulares populares. 2009. 150 f. Dissertação (Mestrado em Sociologia da Educação) - Universidade de São Paulo, São Paulo, 2009.

NASCIMENTO, A. Universidade e cidadania: o movimento dos Cursos Pré-Vestibulares Populares. Lugar Comum, v. 17, p. 45- 60, 2002.

NASCIMENTO, A. O Movimento dos Cursos Pré-Vestibulares para Negros e as Políticas de Cotas nas instituições de ensino superior. João Pessoa: Cadernos Imbondeiro, v.2, n.1, 2012.

SILVA, E. S. Ampliando Futuros: o Curso Pré-Vestibular Comunitário da Maré. 2006. 150 f. Dissertação (Mestrado em Bens Culturais e Projetos Sociais) - Fundação Getúlio Vargas, Rio de Janeiro, 2006.

YAZBEK, M. C. Classes Subalternas e Assistência Social. 9. ed. São Paulo: Cortez, 2016.

ZAGO, N. Cursos pré-vestibulares populares: limites e perspectivas. Perspectiva, Florianópolis, v. 26, n. 1, 149-174, jan./jun. 2008.

ZAGO, N. Pré-vestibular e trabalho docente: caracterização social e mobilização. Revista Contemporânea de Educação, Rio de Janeiro, v.4, p.253-274, 2009.

\footnotetext{
${ }^{1}$ Trata-se de um conceito gramsciano, aplicado às classes exploradas economicamente e também submetidas à exploração nos âmbitos social, econômico e político (YAZBEK, 2015).

${ }^{2}$ A ditadura empresarial-militar (DREIFUSS, 1981) no Brasil compreende o período entre 1964 e 1985 , quando foi iniciado o processo de abertura política.

${ }^{3}$ A Fundação de Amparo à pesquisa do Estado do Rio de Janeiro - FAPERJ é o órgão de fomento que disponibiliza a bolsa oferecida aos docentes do curso Pré-Vestibular Social Teorema.
} 